\title{
Does winter cold really limit the dengue vector Aedes aegypti in Europe?
}

\author{
Isabelle M. Kramer ${ }^{1 *}$, Aljoscha Kreß ${ }^{1}$, Doris Klingelhöfer ${ }^{1}$, Christian Scherer ${ }^{1}$, Parbati Phuyal ${ }^{1}$, Ulrich Kuch', \\ Bodo Ahrens ${ }^{2}$, David A. Groneberg ${ }^{1}$, Meghnath Dhimal ${ }^{3}$ and Ruth Müller ${ }^{1,4}$
}

\begin{abstract}
Background: Aedes aegypti is a potential vector for several arboviruses including dengue and Zika viruses. The species seems to be restricted to subtropical/tropical habitats and has difficulties in establishing permanent populations in southern Europe, probably due to constraints during the winter season. The aim of this study was to systematically analyze the cold tolerance (CT) of Ae. aegypti in its most cold-resistant life stage, the eggs.

Methods: The CT of Ae. aegypti eggs was compared with that of Ae. albopictus which is well established in large parts of Europe. By systematically studying the literature (meta-analysis), we recognized that CT has been rarely tested in Ae. aegypti eggs, but eggs can survive at zero and sub-zero temperatures for certain exposure periods. To overcome potential bias from experimental differences between studies, we then conducted species comparisons using a harmonized high-resolution CT measuring method. From subtropical populations of the same origin, the survival (hatching in \%) and emergence of adults of both species were measured after zero and sub-zero temperature exposures for up to 9 days $\left(3^{\circ} \mathrm{C}, 0^{\circ} \mathrm{C}\right.$ and $-2{ }^{\circ} \mathrm{C}: \leq 9$ days; $-6^{\circ} \mathrm{C}: \leq 2$ days).
\end{abstract}

Results: Our data show that Ae. aegypti eggs can survive low and sub-zero temperatures for a short time period similar to or even better than those of Ae. albopictus. Moreover, after short sub-zero exposures of eggs of both species, individuals still developed into viable adults (Ae. aegypti: 3 adults emerged after 6 days at $-2{ }^{\circ} \mathrm{C}$, Ae. albopictus: 1 adult emerged after 1 day at $-6^{\circ} \mathrm{C}$ ).

Conclusions: Thus, both the literature and the present experimental data indicate that a cold winter may not be the preventing factor for the re-establishment of the dengue vector Ae. aegypti in southern Europe.

Keywords: Cold hardiness, Distribution limits, Cold tolerance, Overwintering, Phenotypic plasticity, Sub-zero exposure, Winter survival

\section{Background}

Aedes aegypti is the main vector for several arboviruses including dengue, chikungunya, yellow fever and Zika viruses [1]. A re-invasion of Ae. aegypti in southern Europe could become a major threat for the European public health systems. Ae. aegypti (Linnaeus, 1762), originally an African mosquito species, had already

\footnotetext{
*Correspondence: kramer@med.uni-frankfurt.de

${ }^{1}$ Institute of Occupational, Social and Environmental Medicine, Goethe University, Frankfurt am Main, Germany

Full list of author information is available at the end of the article
}

been present in Europe in the early 20th century when it spread from the Portuguese Atlantic coast to the Black Sea [2]. According to one hypothesis, the species never established, disappeared in winter and was transported to Europe again in spring every year. After the 1950s, Ae. aegypti disappeared in Europe due to malaria vector control campaigns using DDT (dichlorodiphenyltrichloroethane) indoor treatments, management of urban water collections, and possibly harsher winter climate conditions [3]. Between 1960 and 2000 only a few sporadic

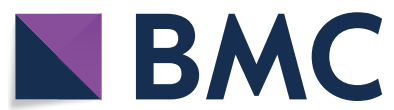

(c) The Author(s) 2020. This article is licensed under a Creative Commons Attribution 4.0 International License, which permits use, sharing, adaptation, distribution and reproduction in any medium or format, as long as you give appropriate credit to the original author(s) and the source, provide a link to the Creative Commons licence, and indicate if changes were made. The images or other third party material in this article are included in the article's Creative Commons licence, unless indicated otherwise in a credit line to the material. If material is not included in the article's Creative Commons licence and your intended use is not permitted by statutory regulation or exceeds the permitted use, you will need to obtain permission directly from the copyright holder. To view a copy of this licence, visit http://creativeco mmons.org/licenses/by/4.0/. The Creative Commons Public Domain Dedication waiver (http://creativecommons.org/publicdomain/ zero/1.0/) applies to the data made available in this article, unless otherwise stated in a credit line to the data. 
records of Ae. aegypti occurrence were reported from Italy, Israel and Turkey [2]. The species established on Madeira in 2004 [4] and it is known that it started to repopulate the northern coast of the Black Sea in 2007 [5]. In 2010, Ae. aegypti was for the first time detected in the Netherlands. However, control measures with adulticides and larvicides have been effective in this country [6]. By comparison, Aedes (Stegomyia) albopictus (Skuse, 1894) spread in the last 30-40 years from East Asia and islands of the western Pacific and Indian Ocean (subtropical/ tropical areas) to all continents except Antarctica [7, 8]. In Europe, Ae. albopictus has been reported in 26 countries and is established in 20 of these countries $[9,10]$. The massive spread of Ae. albopictus and the establishment of permanent populations especially in northern Europe was possibly caused by the strong ecological plasticity of the species which allows for its rapid adaptation to different kinds of habitats and even for its survival under mild winter conditions $[11,12]$. Sub-zero temperatures affect Ae. albopictus depending on the origin of populations (temperate, subtropical or tropical; [12]) and photoperiod (i.e. diapausing or non-diapausing eggs; [13-16]). In temperate regions, Ae. albopictus can adapt to cold winters by producing dormant or so-called diapausing eggs [12]. Aedes aegypti lacks diapause and thus seems to be more restricted to subtropical and tropical habitats. Therefore, it has been assumed that Ae. aegypti has difficulties to establish permanent populations in Europe that can overwinter under the prevailing climatic conditions. In general, the mechanism of the Aedes larvae to survive within the eggshell at low temperatures is defined as the cold hardiness of eggs (reviewed in [13]). Underlying mechanisms of CT in Ae. albopictus eggs are reviewed by Kreß et al. [17]. Several cold tolerance (CT) studies with Ae. albopictus eggs [13, 15, 17-30] and Ae. aegypti eggs [20, 22, 27, 29-36] have already been conducted. Within this approach, CT of South Asian populations of the same origin of both species was evaluated for the first time.

The aim of this study is to compare the CT of the eggs of Ae. aegypti and Ae. albopictus by systematically reviewing the respective literature and conducting a meta-analysis, and by experimentally testing their eggs in a new comparative set-up using a high-resolution CT measuring method [17]. Taking the distribution of both species into account, we hypothesized that Ae. albopictus is in general more cold-hardy than Ae. aegypti.

\section{Methods}

\section{Meta-analysis}

A meta-analysis of the published CT data of Ae. aegypti and Ae. albopictus was conducted in accordance with the PRISMA guidelines (see also Additional file 1).
All databases indexed in Web of Science (WoS) were searched for articles published until the 25th of October 2019 including Web of Science Core Collection, Biological Abstracts, BIOSIS Citation Index, Current Contents Connect, Data Citation Index, Derwent Innovations Index, KCI-Korean Journal Database, Medline, Russian Science Citation Index, SciELO Citation Index and Zoological Record. Only English language publications were included. A WoS topic search that included title, abstract and keywords was applied including the following terms: (i) species: Aedes AND albopictus OR aegypti; (ii) life stage of CT testing: egg; (iii) definition of CT: cold tolerance, cold hardiness, cold resistance, overwinter, subzero exposure.

In the meta-analysis, we included only studies that complied with these inclusion criteria and contained data of temperature, exposure time and hatching success defined as survivorship after sub-zero exposure. Only studies referring to zero and subzero temperatures $\left(\leq 0{ }^{\circ} \mathrm{C}\right)$ were used for further analysis. The references of the retrieved articles were also checked for relevant articles; this resulted in the identification of six additional articles that fulfilled the inclusion criteria. Out of the total of 93 retrieved articles matching our inclusion criteria, 22 articles remained relevant for the meta-analysis. One matching article was excluded because it was not accessible [37]. Some data points had to be excluded either due to an incorrect labelling of graphs by authors or missing exact data on minimum temperature or survivorship [20,31, 33, 34, 36].

The following data parameters were extracted and captured in table format: species, test temperatures, exposure time, rearing conditions (diapause or nondiapause), origin of populations tested, climatic zones of the origin (tropics and temperate (subtropics and tropics were summarized as tropics)), generation tested, survivorship, mortality, hatching (positive or negative), acclimation phase (presence, absence, and differences), type of study (laboratory or field), replicates (presence or absence), controls (presence or absence), number of eggs tested, rearing to life stage (larvae, pupae, adult), bleaching of unhatched eggs (yes or no), comment (if necessary regarding the extracted data), author, year, title, origin of publication, and limitations of study. If original data was needed for correct data extraction, corresponding authors provided original data on request [17, 22].

A detailed description of the extracted data and differences between studies are provided in Additional file 2. Extracted and included data points are given in Additional file 2: Tables S1, S2, respectively. The data points that were excluded from the meta-analysis and their respective exclusion arguments are presented in Additional file 2: Table S3. If only information about 
survivorship was given, mortality was calculated and vice versa. If precise information about the start and end dates of experiments were missing, especially in field studies, the exposure time was estimated (detailed calculation in Additional file 2: Table S4). The minimum temperature in field studies was always used for analysis despite temperature deviations during the exposure time. Referring to the approach described in [30] it was possible to extract minimum temperature from the given exposure times from the website of the National Oceanic and Atmospheric Administration (https://w2.weather.gov/ climate/xmacis.php?wfo=pah). If necessary, exact survivorship could be calculated from pixels of extracted figures (Additional file 2: Table S5). Survivorship, exposure time and temperature were analyzed by generating threedimensional plots separated for both species as well as for both study types (laboratory or field) using RStudio Version 1.1.423 [38]. The proportion of data points tested at different temperature levels (in total $100 \%$ ) and time points (in total 100\%) and analyzed parameters (each parameter in total 100\%) were analyzed for each species and type of study. Minimum, maximum and mean of tested exposure time and temperature were examined. As additional parameters for meta-analysis, the number of generations, the absence or presence of replicates and controls, (non)acclimation to different temperatures before sub-zero exposure, the bleaching of unhatched eggs after sub-zero experiment, and whether hatched larvae were reared to pupal stage or adulthood after subzero exposure were included. Furthermore, publication year, the country of origin of publications (based on the institutional affiliation of the first author) and the origin of the tested mosquito populations were examined.

\section{Cold tolerance experiment}

The CT of eggs of two Aedes species from the same South Asian sampling site was assessed at cold temperatures (CT1: $3{ }^{\circ} \mathrm{C}\left(\leq 9\right.$ days), $0{ }^{\circ} \mathrm{C}(\leq 4$ days)) and (sub)zero temperatures $\left(\mathrm{CT} 2: 0{ }^{\circ} \mathrm{C},-2{ }^{\circ} \mathrm{C}(\leq 8\right.$ days $)$ and $-6{ }^{\circ} \mathrm{C}$ $(\leq 2$ days)). Therefore, first the eggs were cooled down in a stepwise manner until exposure temperatures were reached; secondly, the eggs were exposed to sub-zero temperature for a certain period of time; thirdly, the eggs were subsequently warmed up and hatching stimulus was provided. The CT of eggs was determined in each treatment by quantifying survivorship (number of hatched larvae and the percentage that survive to adult stage).

The experiments reported herein, are to the best of our knowledge, the first CT studies of Ae. aegypti and Ae. albopictus eggs from a South Asian population (Fig. 1). Eggs of both species were collected in Chitwan $\left(27^{\circ} 39^{\prime} 03.8^{\prime \prime} \mathrm{N}, 84^{\circ} 24^{\prime} 43.1^{\prime \prime} \mathrm{E}\right)$, a lowland region of Nepal with a subtropical climate, in November 2017, shipped to the Department of Environmental Toxicology \& Medical Entomology, Institute of Occupational, Social and Environmental Medicine, Goethe University Frankfurt am Main, Germany, and reared to adulthood under quarantine conditions [39]. For this purpose, eggs were placed into yeast solution and the hatching of larvae was induced [39]. L2 larvae were moved into 11 vessels filled with water and were fed ad libitum with ground fish food (TetraMin flakes, Tetra, Germany; [40]). Pupae were individually moved into $2 \mathrm{ml}$ tubes. After their emergence, water was removed and adult species identity determined under a stereo microscope with 50-fold magnification (SMZ-171; Motic ${ }^{\circledR}$ Deutschland GmbH, Wetzlar, Germany). Adults of one species were released into a quarantine cage [39]. The breeding procedure (of F0 and F1) took place in a climate chamber with a light:dark cycle of $16: 8 \mathrm{~h}$ (non-diapausing conditions) at $25 \pm 0.44{ }^{\circ} \mathrm{C}$ and $80 \pm 7.95 \%$ relative humidity. Females were fed with human blood approximately every second day [39]. Deposited eggs were counted on filter paper and stored at $25.1 \pm 0.1{ }^{\circ} \mathrm{C}$ and $84.8 \pm 3.3 \%$ relative humidity until the start of the experiments.

To determine CT, the high-resolution measuring method introduced by [17] was applied. In two CT experiments, eggs of Ae. aegypti and Ae. albopictus were exposed to cold temperatures (CT1) and (sub)zero temperatures (CT2) versus control conditions $\left(25{ }^{\circ} \mathrm{C}\right)$ for 0.5 to 9 days (Table 1 ). Results of the CT1 experiment encouraged us to test the survivorship of Ae. aegypti eggs at sub-zero temperatures. In CT1, 2160 eggs of the $F_{1}$ laboratory generation of Ae. aegypti were used. In CT2, 1600 eggs of Ae. aegypti and 1500 eggs of Ae. albopictus of the $\mathrm{F}_{2}$ laboratory generations were used. For each experimental treatment, 120 eggs were filled in $0.2 \mathrm{ml}$ tubes in CT1, and 100 eggs in CT2, respectively. Those tubes were cooled in a $5{ }^{\circ} \mathrm{C}$ and $24 \mathrm{~h}$ stepwise manner from $25^{\circ} \mathrm{C}$ downwards. In CT1, PCR cyclers (TProfessional Basic and T3 Thermocycler; Biometra GmbH, Jena, Germany) were programmed to hold constantly all temperatures until $0{ }^{\circ} \mathrm{C}$. In CT2, PCR-cyclers were programmed to hold constantly all temperatures until $5{ }^{\circ} \mathrm{C}$, respectively. The accuracy and function of PCR cyclers was checked using a laser temperature measurement device (Testo $\mathrm{SE} \& \mathrm{Co.KGaA}$, Lenzkirch, Germany). In CT2, $0{ }^{\circ} \mathrm{C}$ samples were installed in a cold-water thermostat by placing $0.2 \mathrm{ml}$ tubes in $50 \mathrm{ml}$ tubes in the thermostat (RM 20 LAUDA, Dr R. Wobser GmbH \& CO. KG, Lauda-Königshofen, Germany). A cooling box connected to a thermostat (Model F12-ED; Julabo GmbH, Seelbach, Germany) was used to carry out the $-2{ }^{\circ} \mathrm{C}$ exposure of eggs [17]. The temperature at the exact position of the egg tubes in the cooling box was measured daily using a data logger (HOBO UX100-011; Onset, Cape Cod- MA, USA). On 


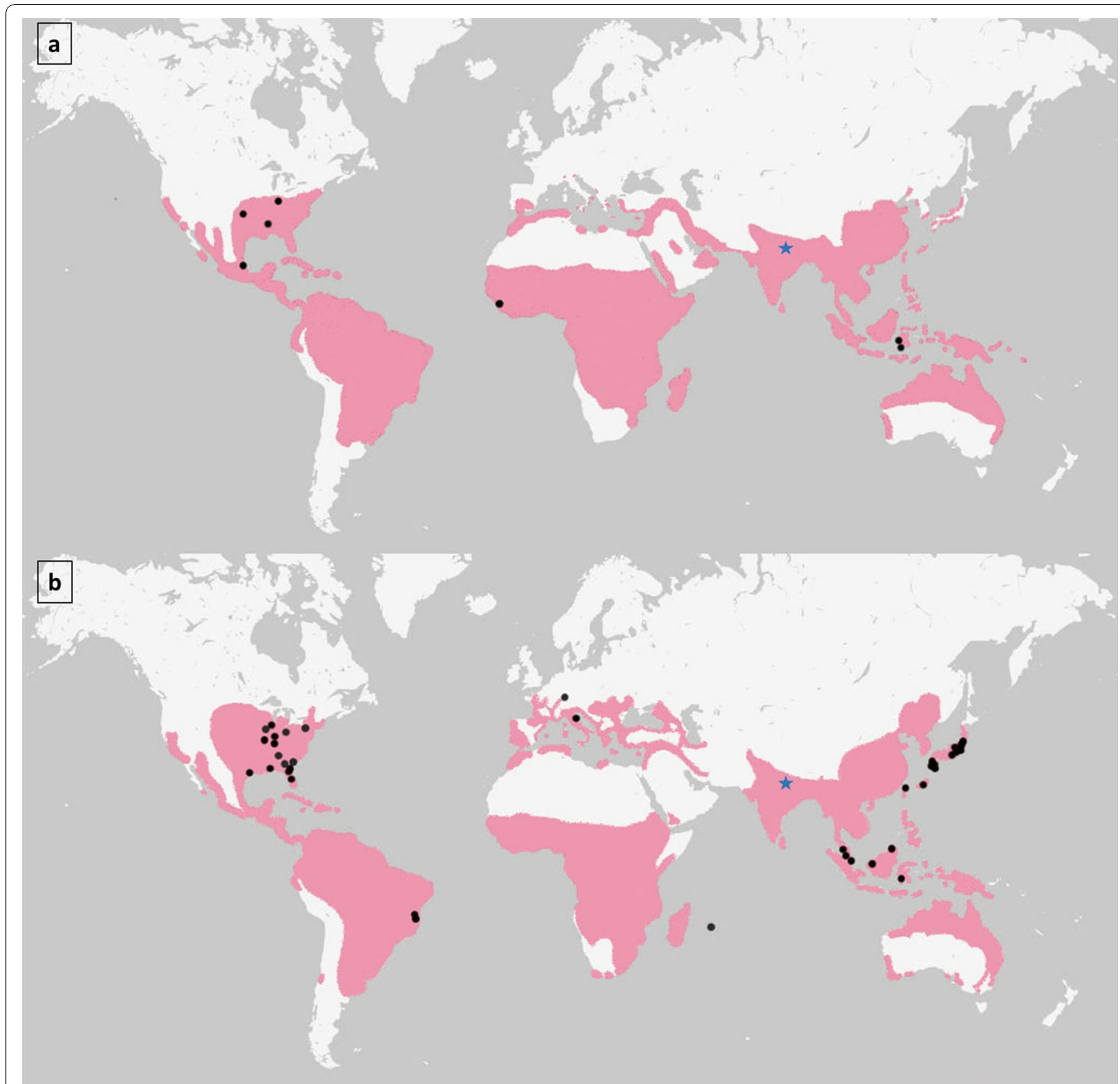

Fig. 1 Origin of Ae. aegypti (a) and Ae. albopictus (b) populations with known cold tolerance (CT). The predicted distribution of the two species according to [47] is shaded in magenta. The origin of populations examined in CT studies included in the meta-analysis are marked with black dots. The sampling site of mosquitoes used for CT experiments in the present study (Chitwan, Nepal) is marked with a blue star (source of map: https:// mapstyle.withgoogle.com/)

average, a temperature of $-1.9 \pm 0.2^{\circ} \mathrm{C}$ was measured in the cooling box. It has to be noted, that short-term $>0{ }^{\circ} \mathrm{C}$ data resulting from the opening of the cooling box during handling were excluded from the analysis. The water/glycol tank of a thermostat (Model F12-ED; Julabo GmbH) was used for $-6{ }^{\circ} \mathrm{C} \mathrm{CT}$ treatments. The temperature at the exact position of the egg tubes in the $-6{ }^{\circ} \mathrm{C}$ and $0{ }^{\circ} \mathrm{C}$ thermostat experiments was confirmed daily using a thermometer (Thermometer Deluxe, error rate $0.1{ }^{\circ} \mathrm{C}$;
Lucky Reptile, Waldkirch, Germany); no temperature variation over the experimental time was observed.

To induce hatching after the exposure of eggs to specific CT treatments (Table 1), eggs were placed into 12 -well culture plates with $\sim 10$ eggs and $2 \mathrm{ml}$ of hatching solution [39] per cavity and exposed at $25^{\circ} \mathrm{C}$ to continuous light for $24 \mathrm{~h}$, and then to a 16:8 h light:dark cycle for another six days (CT1) or five days (CT2). One well was regarded as one replicate per treatment $(\mathrm{CT} 1$ : 
Table 1 Cold tolerance (CT) experiments, CT1 with Ae. aegypti eggs and CT2 with Ae. aegypti and Ae. albopictus eggs

\begin{tabular}{|c|c|c|c|c|c|c|c|c|c|c|c|c|c|c|c|}
\hline \multirow{2}{*}{$\begin{array}{l}\text { CT experiment } \\
\text { CT1: Ae. aegypti }\end{array}$} & \multirow{2}{*}{$\begin{array}{l}\text { Generation } \\
\text { F1 }\end{array}$} & \multirow{2}{*}{$\begin{array}{l}\text { Temperature } \\
\left({ }^{\circ} \mathrm{C}\right)\end{array}$} & \multicolumn{13}{|c|}{ Exposure time (days) } \\
\hline & & & 0.5 & 1 & 1.5 & 2 & 2.5 & 3 & 3.5 & 4 & & & & & \\
\hline & & 3 & & 1 & & 2 & & 3 & & 4 & 5 & 6 & 7 & & 9 \\
\hline \multirow[t]{3}{*}{ CT2: Ae. aegypti } & $\mathrm{F} 2$ & 0 & & 1 & & 2 & & & & 4 & & & & 8 & \\
\hline & & -2 & & 1 & & 2 & & 3 & & $4^{\mathrm{a}}$ & & 6 & & 8 & \\
\hline & & -6 & & 1 & & 2 & & & & & & & & & \\
\hline \multirow[t]{3}{*}{ CT2: Ae. albopictus } & $\mathrm{F} 2$ & 0 & & 1 & & 2 & & & & 4 & & 6 & & 8 & \\
\hline & & -2 & & 1 & & 2 & & 3 & & 4 & & 6 & & 8 & \\
\hline & & -6 & & 1 & & 2 & & & & & & & & & \\
\hline
\end{tabular}

a Technical error, two treatments instead of one

Notes: Experimental conditions including the laboratory generation of species, exposure temperature and exposure times (treatment, in days) are given. In parallel, two negative controls (NC) were run at $25^{\circ} \mathrm{C}$ during each experiment

10-12 replicates; CT2: 8-10 replicates). Each treatment represented 94-124 (CT1) and 70-106 (CT2) eggs, respectively.

Survivorship after sub-zero temperature exposure was determined using a stereo microscope with 50-fold magnification (SMZ-171, Motic ${ }^{\circledR}$; Deutschland $\mathrm{GmbH})$. The minimum requirement for survivorship was defined as the head of the larva being visible outside the chorion [17]. In order to close knowledge gaps in the literature, we also reared both species after sub-zero exposure in the CT2 experiment to the adult stage which is most relevant in a medical context. The sex of adult specimens was checked, and species identity verified as described above.

\section{Statistical analysis of cold tolerance experiments}

The percentage of survivorship per cavity was calculated for all CT treatments and negative controls (NC). The survivorship of eggs exposed to $25^{\circ} \mathrm{C}(\mathrm{NC})$ was analyzed for normality of residuals (D’Agostino \& Pearson) and for differences between NCs (unpaired t-test). All NCs passed the normality test except one out of the two Ae. albopictus controls (sample size was too small). NCs did not differ significantly from each other, and CT treatments were normalized to the mean of NCs. The subzero temperature response of Aedes eggs over time was analyzed with the nonlinear regression model [inhibitor] vs normalized response. After outlier elimination via robust regression outlier removal test (CT1: no outliers; CT2: Ae. aegypti $-6{ }^{\circ} \mathrm{C}$ one outlier; CT2: Ae. albopictus $-2{ }^{\circ} \mathrm{C}$ one outlier), all data sets passed the normality of residuals test (D’Agostino \& Pearson). $\mathrm{LT}_{50}$ values ( $50 \%$ lethal time $=$ time when $50 \%$ of eggs did not hatch after treatment) were calculated for normalized data and compared, if possible [17]. In addition, the response to $-2{ }^{\circ} \mathrm{C}$ or $0{ }^{\circ} \mathrm{C}$ exposure for 8 days in the $\mathrm{CT} 2$ experiment were compared intra- and interspecifically using a 2-way ANOVA following Tukey's post-hoc test.

Finally, the number of emerged adults per NC and CT treatment that can contribute to spring populations were evaluated. In addition, the percentage of adults belonging to the wrong species (technical error) was analyzed. Moreover, survival of hatched larvae up to adult stage after extreme exposure was analyzed per test temperature $\left(0{ }^{\circ} \mathrm{C},-2{ }^{\circ} \mathrm{C}\right.$ and $\left.-6{ }^{\circ} \mathrm{C}\right)$ and compared between species using Kaplan-Meier survival analysis (log-rank (Mantel-Cox) test). By means of Kaplan-Meier estimator, the survival function from hatched L1 larvae (set as $100 \%)$ to emerged adults after previous egg exposure to $1,2,4$ and 8 days to $0{ }^{\circ} \mathrm{C}$ (day 6 was excluded because it is not present in Ae. aegypti), to 1, 2, 3, 6 and 8 days to $-2{ }^{\circ} \mathrm{C}$ (for a better comparison, day 4 was excluded due to technical error for Ae. aegypti described in Table 1) as well as 1 and 2 days to $-6{ }^{\circ} \mathrm{C}$, respectively, was calculated. All statistical analyses for CT experiments were conducted using Prism ${ }^{\circledR}$ (Version 7, GraphPad Software Inc., San Diego-CA, USA).

\section{Results}

Meta-analysis

Articles or studies that matched our inclusion criteria had been published from four countries: USA (15 articles), Japan (3 articles), Germany (3 articles) and Great Britain (1 article). The earliest study was conducted in 1910 and the latest in 2019. Most articles were published from 1980-1996. One of the earliest studies of 1916 was found by checking the summary of Christophers [41]. From the year 2000 onwards, only six articles were published; two of them in 2019.

In total, 642 relevant data points for temperatures below $0{ }^{\circ} \mathrm{C}$ and respective exposure time and survivorship/mortality could be extracted: 89 data points for $A e$. 


\section{$a$
$\frac{7}{0}$
$\frac{\pi}{0}$
$\frac{0}{\pi}$}
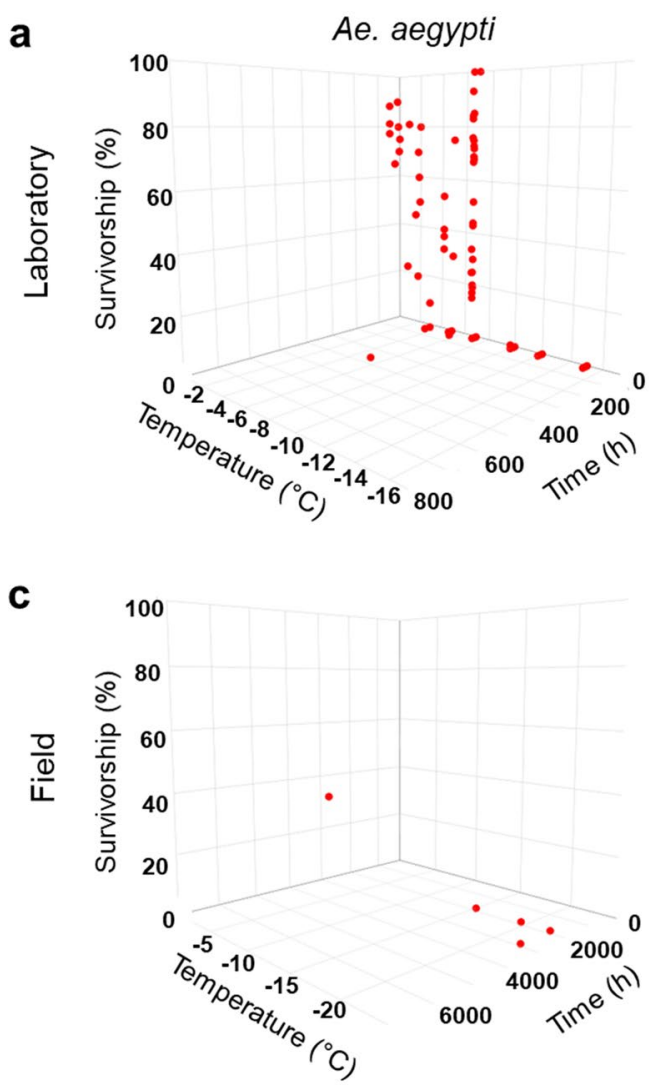

b

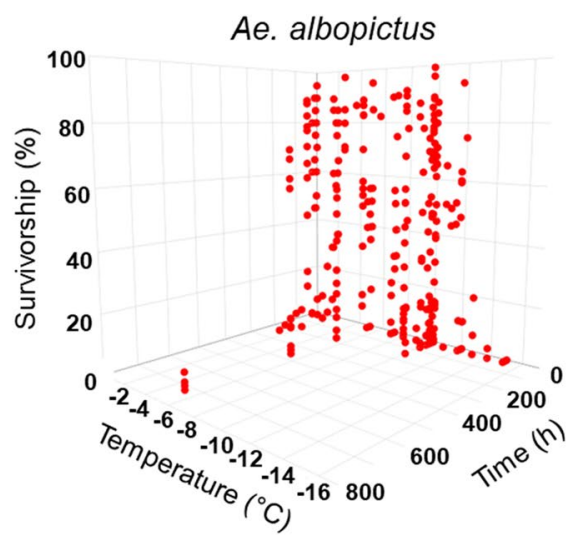

d

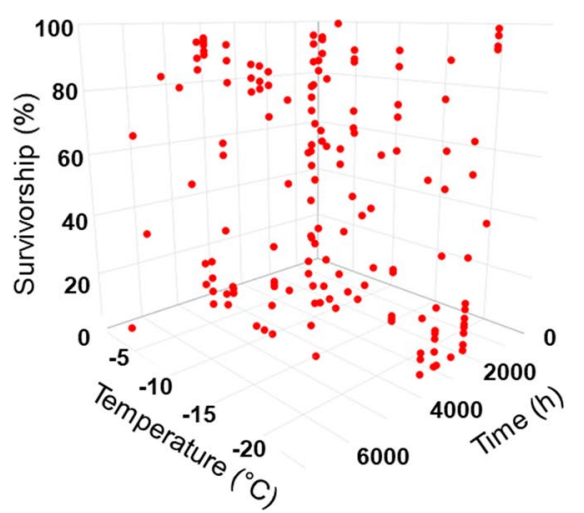

Fig. 2 Survivorship (\%) of Ae. aegypti $(\mathbf{a}, \mathbf{c})$ and Ae. albopictus $(\mathbf{b}, \mathbf{d})$ after exposure to different temperatures $\left({ }^{\circ} \mathrm{C}\right)$ over time (h) under laboratory $(\mathbf{a}, \mathbf{b})$ or field (c, d) conditions

aegypti and 553 data points for Ae. albopictus (Fig. 2). Thereof, $12.6 \%$ stem from laboratory studies with $A e$. aegypti, $56.2 \%$ from laboratory studies with Ae. albopictus, 1.3\% from field studies with Ae. aegypti, and 29.9\% from field studies with Ae. albopictus. In total, ten different Ae. aegypti populations (with three populations whose exact origin is unclear) and 41 different populations of Ae. albopictus were tested (Fig. 1, unclear population origins not shown).

For both species, temperatures $>-15{ }^{\circ} \mathrm{C}$ were more often examined in laboratory studies, whereas temperatures $<-15{ }^{\circ} \mathrm{C}$ were more often examined in field studies (Table 2). The mean test temperatures for $A e$. aegypti eggs in the laboratory were $-6.2 \pm 3.9{ }^{\circ} \mathrm{C}$ for $32.6 \pm 76.4 \mathrm{~h}$, and for Ae. albopictus eggs $-7.7 \pm 4.0^{\circ} \mathrm{C}$ for $84.1 \pm 202.4 \mathrm{~h}$. Most laboratory studies applied short exposure times below $24 \mathrm{~h}$. The field-tested mean temperature and exposure time was $-17.0 \pm 6.6{ }^{\circ} \mathrm{C}$ for $2118 \pm 468.3 \mathrm{~h}(12.6 \pm 2.8$ weeks $)$ for Ae. aegypti, and $-10.8 \pm 7.6{ }^{\circ} \mathrm{C}$ for $2640.6 \pm 1351.4 \mathrm{~h}(15.7 \pm 8.0$ weeks $)$ for Ae. albopictus.
For Ae. aegypti, even longer exposure times of $360 \mathrm{~h}$ $\left(-5{ }^{\circ} \mathrm{C}\right.$, laboratory), $1848 \mathrm{~h}\left(-15^{\circ} \mathrm{C},-19.4{ }^{\circ} \mathrm{C}\right.$ and $-22{ }^{\circ} \mathrm{C}$, field) and $2880 \mathrm{~h}\left(-22^{\circ} \mathrm{C}\right.$, field $)$ were examined, but $A e$. aegypti eggs could not survive under these conditions [20,30]. Only in one field experiment, survivorship of Ae. aegypti eggs was observed after exposure to $-1.1{ }^{\circ} \mathrm{C}$ for $2976 \mathrm{~h}$ [35]. Thus, the ability of Ae. aegypti eggs for overwintering at sub-zero temperatures in the field has been experimentally proven.

On average, Ae. albopictus eggs survived lower subzero temperatures with longer exposure times than $A e$. aegypti eggs. For example, in the laboratory, 47\% survivorship of temperate non-diapausing Ae. albopictus eggs was observed after exposure to $-10^{\circ} \mathrm{C}$ for $144 \mathrm{~h}$ [27], or $88 \%$ survivorship of tropical non-diapausing Ae. albopictus eggs after exposure to $-10{ }^{\circ} \mathrm{C}$ for $24 \mathrm{~h}$ [29]. Aedes albopictus larvae still hatched from non-diapausing conditioned eggs after exposure to $0{ }^{\circ} \mathrm{C}$ to $-13^{\circ} \mathrm{C}$ for $1 \mathrm{~h}$ to 720 h $[17,20-22,26,27,29]$. Eggs of Ae. albopictus with induced diapause showed survivorship after exposure to $0{ }^{\circ} \mathrm{C}$ to $-14{ }^{\circ} \mathrm{C}$ for $1-144 \mathrm{~h}[22,26,27]$. In the field, 
Table 2 The distribution of reported data points on subzero temperature response of Ae. aegypti and Ae. albopictus at different temperature levels and time points (in percentage)

\begin{tabular}{|c|c|c|c|c|}
\hline \multirow[t]{2}{*}{ Parameter } & \multicolumn{2}{|l|}{ Ae. aegypti } & \multicolumn{2}{|c|}{ Ae. albopictus } \\
\hline & Laboratory & Field & Laboratory & Field \\
\hline \multicolumn{5}{|c|}{ Temperature $\left({ }^{\circ} \mathrm{C}\right)$} \\
\hline$<-15$ & 0.8 & 1.1 & 2.3 & 11.1 \\
\hline-10 to -15 & 1.9 & 0 & 26.8 & 2.8 \\
\hline-5 to -10 & 6.7 & 0 & 16.8 & 7.5 \\
\hline 0 to -5 & 3.3 & 0.2 & 10.3 & 8.6 \\
\hline \multicolumn{5}{|c|}{ Exposure time (h) } \\
\hline $24 \mathrm{~h}$ & 10.1 & 0 & 35.4 & 0 \\
\hline $48 \mathrm{~h}$ & 1.7 & 0 & 8.1 & 0 \\
\hline $72 \mathrm{~h}$ & 0.2 & 0 & 3.1 & 0 \\
\hline $96 \mathrm{~h}$ & 0 & 0 & 0.3 & 0 \\
\hline $300 \mathrm{~h}$ & 0 & 0 & 5.5 & 0.2 \\
\hline $1000 \mathrm{~h}$ & 0.6 & 0 & 3.1 & 2.2 \\
\hline $3000 \mathrm{~h}$ & 0 & 1.3 & 0.8 & 17.1 \\
\hline $7000 \mathrm{~h}$ & 0 & 0 & 0 & 10.4 \\
\hline
\end{tabular}

Notes: The proportion of data points tested at different temperature levels (in total $100 \%$ ) and time points (in total $100 \%$ ) are shown for each species and type of study (laboratory, field)

diapausing eggs of Ae. albopictus showed survivorship after exposure to $-1{ }^{\circ} \mathrm{C}$ to $-22{ }^{\circ} \mathrm{C}$ for $600 \mathrm{~h}$ to $5472 \mathrm{~h}$ $[15,18,19,24,25,28,30]$, whereas non-diapausing eggs showed survivorship after exposure to $0{ }^{\circ} \mathrm{C}$ to $-22^{\circ} \mathrm{C}$ for $336 \mathrm{~h}$ to $6576 \mathrm{~h}[15,23,30]$.

After sub-zero exposure, eggs were reared to adulthood only in one study published in 1938 [31]. However, the latter had to be excluded from our meta-analysis because the survivorship was not reported in numbers, and thus the data could not be analyzed.

Differences between the species become apparent when studying the parameters representing the experimental designs of previous studies (Table 3): the two mosquito species had been kept and bred for different periods of time in the laboratory before they were used in the reported experiments; only $3.2 \%$ of the tested $A e$. aegypti belonged to the $<20$ th laboratory-bred generation whereas $50.5 \%$ of the tested Ae. albopictus belonged to the $<20$ th laboratory-bred generation. Per data point, $173.7 \pm 784.7$ eggs were used in Ae. aegypti studies and $197.2 \pm 235.6$ eggs in Ae. albopictus studies. For both species, replicates (Ae. aegypti: 11.5\%; Ae. albopictus: 53.7\%) and controls (Ae. aegypti: 5.8\%; Ae. albopictus: $36.1 \%$ ) were absent in most of the published experiments. In some studies, eggs had been pre-exposed to different temperatures or different levels of relative humidity. This may have influenced survivorship. For example, Ae. aegypti were acclimated before sub-zero exposure
Table 3 The distribution of reported data points on subzero temperature response of Ae. aegypti and Ae. albopictus at different analyzed parameters (in percentage)

\begin{tabular}{|c|c|c|}
\hline Parameter & Ae. aegypti & Ae. albopictus \\
\hline \multicolumn{3}{|l|}{ Generations } \\
\hline$<2$ & 1.1 & 6.1 \\
\hline$<5$ & 0.2 & 31.9 \\
\hline$<10$ & 0.0 & 10.6 \\
\hline$<20$ & 1.9 & 1.9 \\
\hline$>20$ & 0.6 & 4.7 \\
\hline Unknown & 10.1 & 31.0 \\
\hline \multicolumn{3}{|l|}{ Replicates } \\
\hline Presence & 2.3 & 29.0 \\
\hline Absence & 11.5 & 53.7 \\
\hline Unknown & 0 & 3.4 \\
\hline \multicolumn{3}{|l|}{ Controls } \\
\hline Presence & 8.1 & 37.5 \\
\hline Absence & 5.8 & 36.1 \\
\hline Unknown & 0 & 12.5 \\
\hline \multicolumn{3}{|c|}{ Acclimation before sub-zero exposure } \\
\hline Presence & 3.1 & 30.5 \\
\hline Absence & 10.8 & 55.6 \\
\hline \multicolumn{3}{|c|}{ Bleaching of eggs after sub-zero experiment } \\
\hline Presence & 3.3 & 48.8 \\
\hline Absence & 10.6 & 34.6 \\
\hline Unknown & 0 & 2.8 \\
\hline \multicolumn{3}{|c|}{ Rearing to... (after sub-zero exposure) } \\
\hline Larvae & 12.9 & 73.7 \\
\hline Pupae & 0.2 & 12.5 \\
\hline Adults & 0 & 0 \\
\hline Unknown & 0.8 & 0 \\
\hline
\end{tabular}

Notes: The proportion of data points tested at analyzed parameters (each parameter in total 100\%) are shown for each species. Analysis parameters are number of generations, absence or presence of replicates, controls, acclimation to different temperatures before sub-zero exposure, bleaching of unhatched eggs after sub-zero experiment, and if larvae were further reared to pupae or adults after sub-zero exposure

in $3.1 \%$ of all extracted data points and Ae. albopictus in $30.5 \%$, respectively. After (sub)zero exposure, $12.9 \%$ of all extracted data points on Ae. aegypti eggs reared individuals only to larval stage and $0.2 \%$ to pupal stage. In contrast, $73.7 \%$ of all extracted data points of Ae. albopictus eggs were reared to larval stage and $12.5 \%$ to pupal stage. Larvae of either species were never reared to adulthood in any of the included studies.

\section{Cold tolerance experiments}

The CT1 experiment revealed that $3{ }^{\circ} \mathrm{C}$ did not have a high influence on the survivorship of Ae. aegypti eggs during the exposure times tested (Fig. 3a). Survivorship 

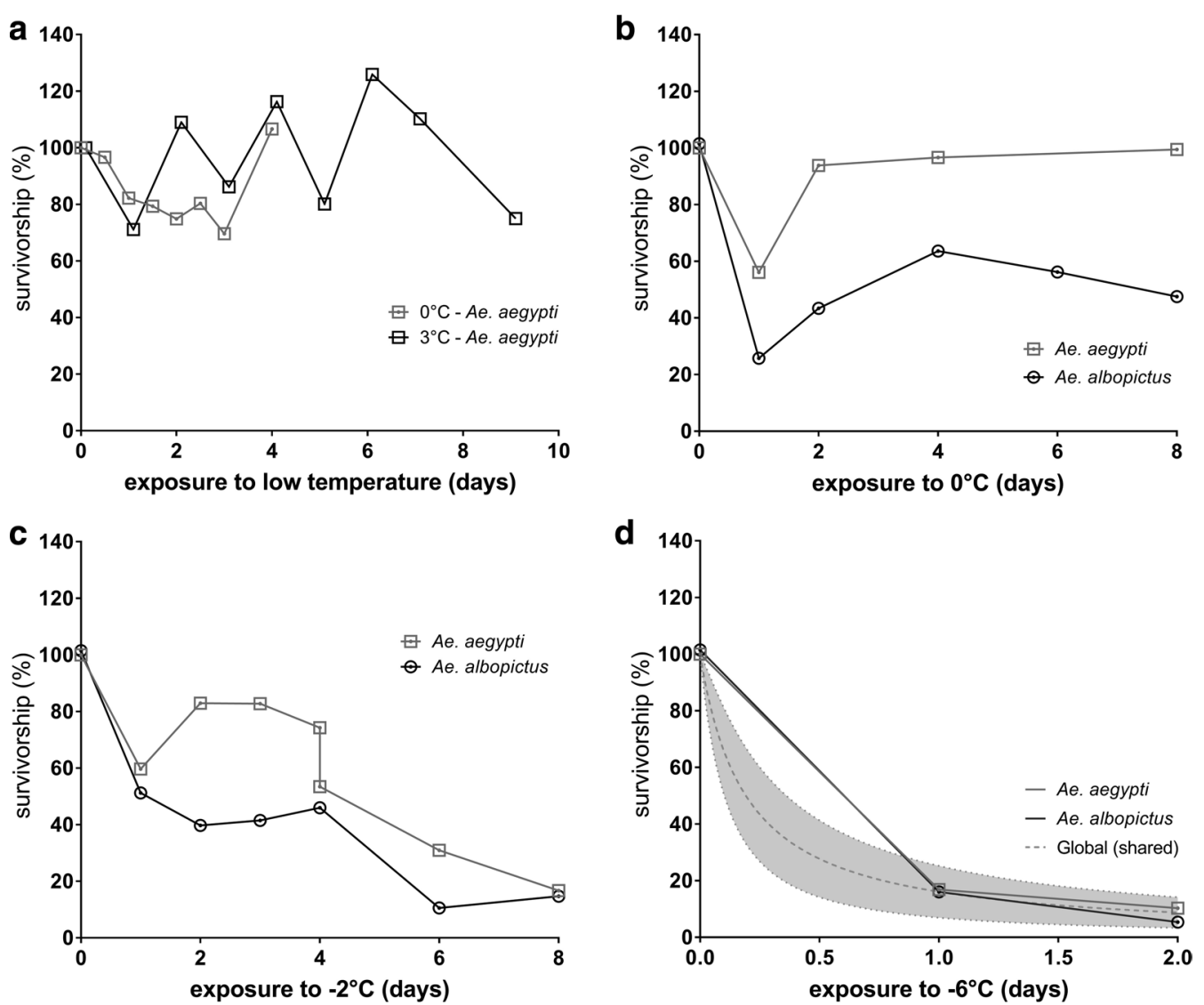

Fig. 3 Cold tolerance (CT) of Ae. aegypti and Ae. albopictus eggs. Mean survivorship (normalized to $25^{\circ} \mathrm{C}$ controls, in \%) after exposure of Ae. aegypti eggs to $0{ }^{\circ} \mathrm{C}$ and $3{ }^{\circ} \mathrm{C}$ for a maximum of 9 days in experiment $\mathrm{CT} 1$ (a), and eggs of both species to $0{ }^{\circ} \mathrm{C}(\mathbf{b}),-2{ }^{\circ} \mathrm{C}$ (c) and $-6{ }^{\circ} \mathrm{C}(\mathbf{d})$ for a maximum of 8 days in experiment CT2. In addition, the global (shared) CT model is shown (d). Mean unnormalized survivorship of controls CT1:47.8-51.1\%; CT2: Ae. aegypti: 50.5-51.3\%; Ae. albopictus: 52.7-53.6\% (raw data of treatments in Additional file 2: Table S1)

Table $4 \mathrm{LT}_{50}$ values and 95\% confidence intervals (Cl) of [inhibitor] vs normalized response models for all data sets

\begin{tabular}{|c|c|c|c|c|c|c|c|c|}
\hline \multirow{2}{*}{$\begin{array}{l}\text { Experiment } \\
\text { Species }\end{array}$} & \multicolumn{2}{|l|}{ CT1 } & \multicolumn{6}{|l|}{$\mathrm{CT} 2$} \\
\hline & \multicolumn{2}{|c|}{ Ae. aegypti } & Ae. aegypti & Ae. albopictus & Ae. aegypti & Ae. albopictus & Ae. aegypti & Ae. albopictus \\
\hline Egg exposure to & $0{ }^{\circ} \mathrm{C}$ & $3{ }^{\circ} \mathrm{C}$ & $0{ }^{\circ} \mathrm{C}$ & $0^{\circ} \mathrm{C}$ & $-2^{\circ} \mathrm{C}$ & $-2^{\circ} \mathrm{C}$ & $-6^{\circ} \mathrm{C}$ & $-6^{\circ} \mathrm{C}$ \\
\hline$R^{2}$ & 0.003 & -0.002 & -0.04 & 0.09 & 0.33 & 0.61 & 0.814 & 0.79 \\
\hline $\mathrm{LT}_{50}$ & 12.1 & 371.0 & 94.8 & 3.1 & 4.9 & 1.4 & 0.2 & 0.2 \\
\hline $95 \% \mathrm{Cl}$ of $\mathrm{LT}_{50}$ & $5.8-57.5$ & $39.2-\infty$ & $17.9-\infty$ & $1.5-6.0$ & $3.4-7.1$ & $0.93-2.1$ & $0.1-0.4$ & $0.007-0.4$ \\
\hline
\end{tabular}

Abbreviations: $\mathrm{CT} 1$, cold tolerance experiment number 1; $\mathrm{CT} 2$, cold tolerance experiment number 2

Notes: Comparison of $\mathrm{LT}_{50}$ of [inhibitor] vs normalized response model shows no interspecific significant differences over the exposure time of 2 days at $-6^{\circ} \mathrm{C}(\mathrm{P}: 0.77)$

of Ae. aegypti eggs at $0{ }^{\circ} \mathrm{C}$ still occurred after 4 days (Fig. 3a, Table 4).

In general, the survivorship in CT1 (Ae. aegypti) and CT2 (both species) experiments showed high variance after egg exposure to sub-zero temperatures as indicated by low regression coefficients and restricted confidence intervals (Table 4). The regression coefficients and results of replicates test indicate that the [inhibitor] vs normalized response model adequately describes the CT2 $-6{ }^{\circ} \mathrm{C}$ datasets for both species and the $\mathrm{CT} 2-2{ }^{\circ} \mathrm{C}$ dataset for Ae. albopictus.

In experiment $\mathrm{CT} 2$, the factor temperature caused a total variation of egg survivorship of $36.0 \%\left(F_{(1}\right.$, $\left.{ }_{28)}=20.5, P=0.0001\right)$, the factor species $7.8 \%\left(F_{(1,}\right.$ 
$\left.\left.{ }_{28}\right)=4.5, P=0.0440\right)$, and their interactions $6.7 \%\left(\mathrm{~F}_{(1,}\right.$ $\left.{ }_{28}=3.8, P=0.0606\right)$, respectively. The responses of Ae. albopictus eggs to $0{ }^{\circ} \mathrm{C}$ and $-2{ }^{\circ} \mathrm{C}$ exposure for 8 days were not significantly different. In contrast, the responses of Ae. aegypti eggs to (sub)zero temperature exposure for 8 days differed significantly (2-way ANOVA following Tukey's post-hoc test: $P=0.0003$ ). The eggs of Ae. aegypti were more tolerant to $0{ }^{\circ} \mathrm{C}$ and $-2{ }^{\circ} \mathrm{C}$ exposure for 8 days if compared to Ae. albopictus eggs (Fig. 3b, c). At day 8, interspecific differences became apparent in $0{ }^{\circ} \mathrm{C}$ treatments (2-way ANOVA following Tukey's post-hoc test: $P=0.0353$ ), but significant interspecific differences vanished in $-2{ }^{\circ} \mathrm{C}$ treatments. After 8 days of exposure to $0{ }^{\circ} \mathrm{C}$, the survivorship of both species was higher (Ae. aegypti: 99.4\%; Ae. albopictus: $47.5 \%$ ) than after 8 days exposure to $-2{ }^{\circ} \mathrm{C}$ (Ae. aegypti: $16.7 \%$; Ae. albopictus: $14.7 \%$; Fig. 3c).

In both species, the survivorship of eggs was low after exposure to $-6{ }^{\circ} \mathrm{C}$ for 2 days and then did not differ between species (Table 4). However, survivorship at $-6{ }^{\circ} \mathrm{C}$ after 2 days still occurred in both species (Ae. aegypti $=10.3 \%$; Ae. albopictus $=5.4 \%$; Fig. 3d).
Ae. aegypti and Ae. albopictus hatched after exposure to $-2{ }^{\circ} \mathrm{C}$ for 8 days and $-6{ }^{\circ} \mathrm{C}$ for 2 days, not all larvae developed until adult stage. In total, 301 adults hatched in the Ae aegypti experiment and 169 adults in the Ae. albopictus experiment emerged from eggs after zero and sub-zero temperatures in our experiments. Among these, three Ae. aegypti adults emerged after a 6-day exposure to $-2{ }^{\circ} \mathrm{C}$, and one Ae. albopictus adult emerged after a 1-day exposure to $-6{ }^{\circ} \mathrm{C}$ (detailed description of adult emergence in Additional file 2: Table S6). Estimated survival functions of hatched larvae to emerged adults over exposure time of up to 8 days at $-2{ }^{\circ} \mathrm{C}$ significantly differ (log-rank(Mantel-Cox)test; $d f=1, P=0.0006)$ between Ae. aegypti (50\% reduction of survival: 6 days) and $A e$. albopictus (50\% reduction of survival: 3 days) with $A e$. aegypti showing higher survival of adults (Fig. 4).

Routinely performed microscopical examination of the morphological characters of all emerged mosquitoes in this study revealed that $4.98 \%$ out of the 301 emerged Ae. aegypti were in fact Ae. albopictus, and $12.4 \%$ of the 169 adult Ae. albopictus were actually Ae. aegypti. This highlights the importance of separate verification of taxonomic identity in studies of this type, and mosquito

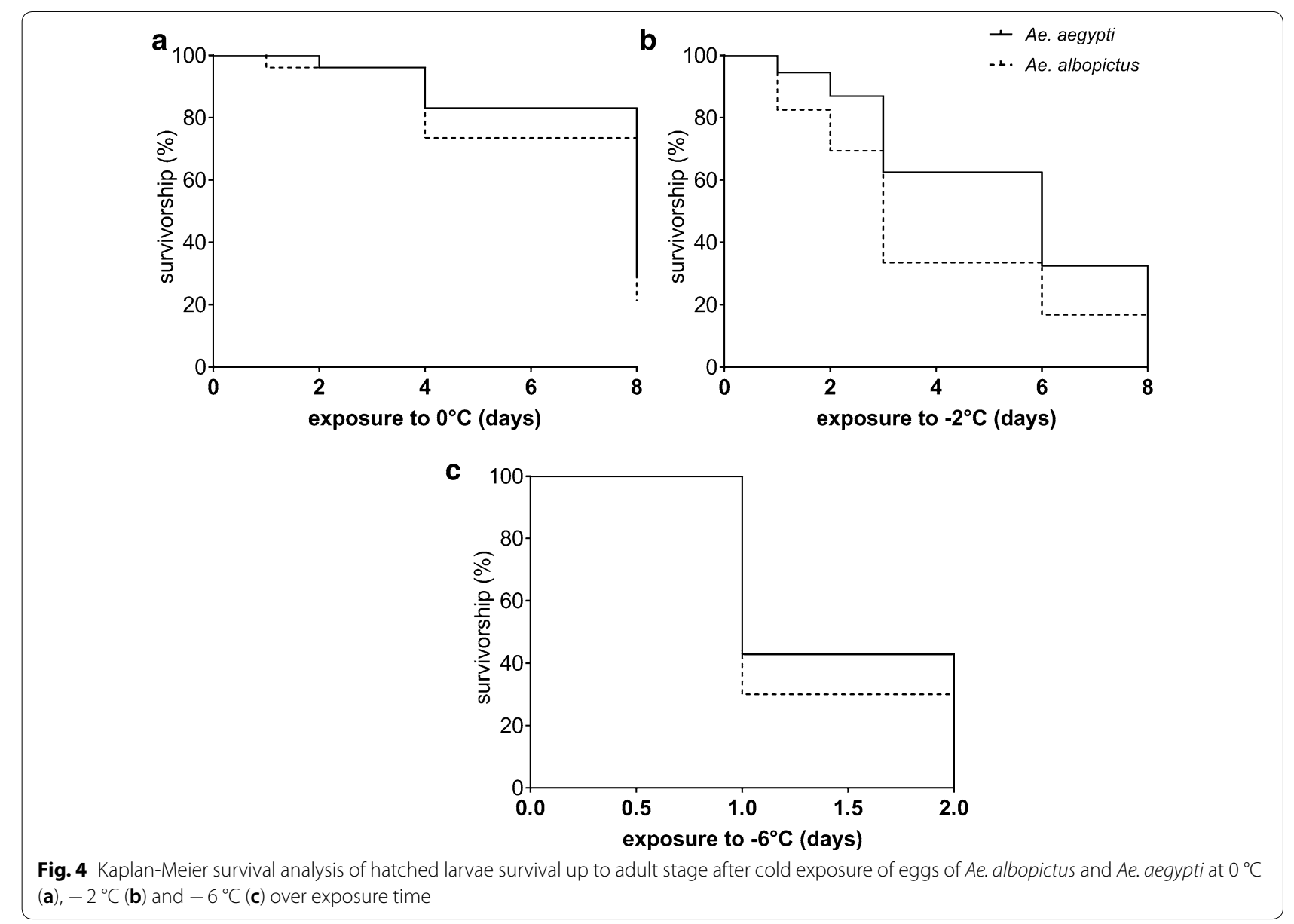


breeding in general. In this case we believe that misidentification during the rearing procedure after sub-zero exposure was the most likely source of error, but contamination during the filling of eggs in tubes (due to electrostatic effects) cannot be excluded.

\section{Discussion}

The merged bibliometric and experimental CT information clearly implies that cold winter temperature is not the limiting factor for the re-establishment of the dengue vector Ae. aegypti in southern Europe. Although the meta-analysis shows that the $\mathrm{CT}$ of Ae. aegypti eggs is underexplored if compared to Ae. albopictus, our new experimental data support the literature data. After an 8-day exposure of subtropical eggs from South Asia to $0{ }^{\circ} \mathrm{C}$, interspecific differences in survivorship are present, but these vanish after 8 days of exposure to $-2{ }^{\circ} \mathrm{C}$ or 2 days of exposure to $-6^{\circ} \mathrm{C}$.

\section{Interspecific comparison of cold tolerance}

Our experimental CT results of South Asian populations are comparable with those of other laboratory studies. For instance, Ae. aegypti eggs of unknown Asian origin were exposed to $0{ }^{\circ} \mathrm{C}$ and $-2{ }^{\circ} \mathrm{C}$ for up to $24 \mathrm{~h}$ [22], Ae. aegypti eggs from Polewali (Sulawesi) and Makassar (Sulawesi) to $0{ }^{\circ} \mathrm{C}$ for up to $48 \mathrm{~h}$ [20], and Ae. aegypti eggs from Freetown (Sierra Leone) to $-1.4{ }^{\circ} \mathrm{C}$ for up to $24 \mathrm{~h}$ and to $-2.2^{\circ} \mathrm{C}$ for up to $24 \mathrm{~h}$ as well as $72 \mathrm{~h}$ [32]. In each of these studies, the survivorship after low/subzero temperature exposure was demonstrated. An African population tested at $-2.2{ }^{\circ} \mathrm{C}$ for three days showed a survivorship of $25 \%$ [32], whereas the normalized mean survivorship in our CT study was $82.8 \%$ after egg exposure to $-2{ }^{\circ} \mathrm{C}$ for three days. Thus, survival of Ae. aegypti differs between populations after sub-zero exposures. In the present study, significant intraspecific differences were detected in Ae. aegypti eggs after 8 days of exposure to $0{ }^{\circ} \mathrm{C}$ versus $-2{ }^{\circ} \mathrm{C}$. Another study showed a survivorship of $65 \%$ of Ae. aegypti eggs after exposure to $0{ }^{\circ} \mathrm{C}$ for $24 \mathrm{~h}$ and $45 \%$ after exposure to $-2{ }^{\circ} \mathrm{C}$ for $24 \mathrm{~h}$ [22]. Similarly, a survivorship of $81 \%$ after 24 h of exposure to $-1.4{ }^{\circ} \mathrm{C}$ and $20 \%$ after $24 \mathrm{~h}$ of exposure to $-2.2{ }^{\circ} \mathrm{C}$ was reported [32]. Hence, a distinct response to $0{ }^{\circ} \mathrm{C}$ versus $-2{ }^{\circ} \mathrm{C}$ was observed in other studies, too. Our present CT study and one other article published in 1938 [31] are the first to report that Ae. aegypti eggs can survive subzero temperatures and develop into viable adults. The success rate of Ae. aegypti reaching adulthood after $0{ }^{\circ} \mathrm{C}$ and $-2{ }^{\circ} \mathrm{C}$ exposure dropped with exposure time and was zero after exposure to $-6{ }^{\circ} \mathrm{C}$ for one or two days. Accordingly, emergence of adults after sub-zero exposure can contribute to population growth in spring even in colder eco-regions.
In comparison to Ae. aegypti, intraspecific differences in Ae. albopictus eggs after 8 days of exposure to $0{ }^{\circ} \mathrm{C}$ or $-2{ }^{\circ} \mathrm{C}$ could not be detected. Non-diapausing Ae. albopictus eggs from Rimini, Italy, did not differ in their response to a $24 \mathrm{~h}$ exposure to $0{ }^{\circ} \mathrm{C}$ or $-2{ }^{\circ} \mathrm{C}$, but Ae. albopictus eggs from Singapore did [22], as also observed in our study for Ae. aegypti from Chitwan, Nepal. Intraspecific variation in cold hardiness between sub-tropical/tropical and temperate populations in Ae. albopictus has often been reported [27]. Only one other study [20] evaluated the CT of both species from the same sampling site, although from slightly different laboratory generations (Makassar, Ae. aegypti: 15th generation, Ae. albopictus: 18th generation; Polewali, Ae. aegypti: 17 th generation, Ae. albopictus: 18 th generation). Eggs of Ae. aegypti from Makassar, South Sulawesi, Indonesia, showed slightly better survivorship at $0{ }^{\circ} \mathrm{C}$ than those of Ae. albopictus from the same locality. In the case of mosquitoes from Polewali, West Sulawesi, Indonesia, the survivorship of Ae. aegypti eggs at $0{ }^{\circ} \mathrm{C}$ was not higher than that of Ae. albopictus eggs [20]. In published studies so far, Ae. albopictus was only reared to larval or pupal stage after (sub)zero temperature exposures of eggs but never to the adult stage. Thus, to the best of our knowledge, our study is the first to demonstrate the successful development of Ae. albopictus into viable adults following sub-zero temperature exposures of eggs. The success rate to reach adulthood after exposure to (sub)zero temperatures was similar in Ae. aegypti and Ae. albopictus at $0{ }^{\circ} \mathrm{C}$ and $-6{ }^{\circ} \mathrm{C}$. At $-2{ }^{\circ} \mathrm{C}$ more adults over exposure duration survived and developed within Ae. aegypti compared to Ae. albopictus, indicating higher $\mathrm{CT}$ at $-2{ }^{\circ} \mathrm{C}$ in Ae. aegypti. However, this result suggests the possibility of both species to establish populations in presence of sub-zero temperatures, which in turn has important epidemiological, prevention and control implications.

\section{Generation influence on cold tolerance}

In order to detect the true $\mathrm{CT}$ of field populations, young laboratory generations need to be examined that have the same age as those used in the CT experiments. Accordingly, the first laboratory generation of Ae. aegypti eggs was used in our CT1 experiment, whereas eggs of the second laboratory generation of both species were examined in the CT2 experiment. In contrast, the majority of studies included in our meta-analysis evaluated different generations of species and populations and/or used laboratory populations that may have adapted to laboratory conditions [17, 20]. Hoffmann et al. [42] examined laboratory adaptation in insects and stated that an increase/ decrease in fitness especially in Diptera in specific trait classes as behavior/reproduction, life history, morphology/size, physiology and stress response was related to 
laboratory adaptation. In mosquitoes, life history and stress responses seem to be influenced the most [42]. Laboratory adaptation was studied in Ae. aegypti for 13 generations using a population size of 100 adults [43]; that study showed that small Ae. aegypti populations can suffer a fitness cost. In our CT study, the eggs of the first and second generations were produced by different numbers of adults. Laboratory adaptation can still be assumed to be a minor factor in the present study in view of the fact that eggs from the first and second generations were used. Hence, we expect our results to closely represent actual reality in the field in regard to examined generations.

\section{High-resolution experimental design}

Our meta-analysis revealed differences regarding the study designs (experimental protocols) for the examination of the survivorship of Ae. aegypti and Ae. albopictus. For instance, hatching media or temperatures differed between studies which may have influenced hatching. Hence, the data extracted from each study may be biased, affecting the comparison of meta-analysis results. In order to minimize effects of laboratory adaptation and consequently artificial biological material effects, a normalization of data to controls is needed to detect true effects. The present CT study is one of a few using controls and replicates, and one of only two studies that normalized the data to the survivorship of the controls [17]. The applied high resolution CT measuring method of Kreß et al. [17] produced reliable results. The negative controls of the second CT generation of Ae. albopictus eggs revealed an $\mathrm{LT}_{50}$ value of $33.6 \mathrm{~h}$ (Table $4,1.4 * 24 \mathrm{~h}$; after normalization to controls). The first and second generation of Ae. albopictus eggs tested by Kreß et al. [17] showed an $\mathrm{LT}_{50}$ value of 10.7-37.1 h. Thus, these results from our CT study are congruent with those reported by Kreß et al. [17] for Ae. albopictus. Normalization has the advantage of making results more reliable and simplifying the comparison of data. Consequently, future CT studies should normalize data to controls in order to exclude differences in the biological materials used for studies.

Seasonal adaptation in Ae. aegypti: The CT of different laboratory generations of both species have been examined by various authors (Additional file 2: Table S1), but in some of those studies it remained unclear when exactly the populations were sampled. In our own CT study, the eggs of Ae. aegypti and Ae. albopictus were sampled in mid-/end of November which is shortly before the start of winter in Nepal. Hence, a seasonal adaptation and consequently higher $\mathrm{CT}$ of the tested egg material, compared to populations sampled in summer, cannot completely be ruled out. So far, there have been no studies regarding a possible seasonal CT adaptation of Ae. aegypti. Ae. aegypti eggs lack diapause, and the CT shown in our experiments is probably already the maximum that can be achieved by eggs of this lowland Nepal population given the fact survivorship after $-6{ }^{\circ} \mathrm{C}$ for 2 days was only $8.59 \%$. In contrast, it is known that eggs of Ae. albopictus can enter diapause and show increased CT to sub-zero temperatures after acclimation to lower temperatures before sub-zero exposure. Therefore, they can adapt to colder seasons. A comparison between temperate and tropical strains of $A e$. albopictus for $24 \mathrm{~h}$ showed that diapausing eggs from temperate strains were more cold-hardy than non-diapausing eggs from tropical strains [22]. If Ae. albopictus eggs from Chitwan (Nepal) are able to enter diapause, higher survivorship at lower temperatures and over longer sub-zero exposure compared to Ae. aegypti could be expected.

A recent study showed a lower hatching response of $A e$. aegypti eggs from Buenos Aires (Argentina) with a shortday parental photoperiod, and a trend to higher hatching with longer egg storage time in all different photoperiod treatment combinations [44]. These authors suggested that Ae. aegypti might have adapted to local climatic conditions which may have or can also cause the evolution of diapause [44]. Thus, experiments on the diapause of Ae. aegypti eggs and the CT of these eggs should be conducted, too. In general, the tolerance of all life stages towards lower/sub-zero temperatures should be experimentally tested because a recent study even reported survival of adult Ae. aegypti and Ae. albopictus after short sub-zero temperature exposures [45].

Moreover, it was shown in Ae. albopictus that F1 crosses of a temperate and tropical strain had a higher CT than eggs from an F1 tropical strain [13, 21]. If the females that had produced the eggs came from temperate strains, higher CT was detected in the eggs compared to those from females of tropical strains [13]. Moreover, back crosses of the F1 generation from temperate strains were more cold tolerant then back crosses from tropical strains [13]. Thus, CT can increase if a mixture of populations from different regions occurs. Due to the globalization of trade and travel the latter is a likely scenario, and it could have a huge impact on the future distribution of Ae. aegypti as well as Ae. albopictus.

\section{Cold tolerance influenced by origin and season}

Our meta-analysis showed that in some other studies (e.g. [20]) the mosquito eggs were cooled down in a stepwise manner until a sub-zero temperature was reached. In our $\mathrm{CT}$ experiment, temperature was decreased from $25^{\circ} \mathrm{C}$ to sub-zero temperatures in only seven days. Usually, seasonal changes do not happen so rapidly and eggs would have longer acclimation phases to lower temperatures which may even increase CT further as shown by Hanson \& Craig [26]. Moreover, in the field fluctuating temperatures and not constant sub-zero temperatures as in 
the described laboratory experiments are present. However, in a field experiment over $2976 \mathrm{~h}$ with a minimum temperature of $-1.1{ }^{\circ} \mathrm{C}$, Hatchett [35] observed that $A e$. aegypti could survive and hatch even under fluctuating low temperatures. Accordingly, the minimum survival temperatures of eggs summarized in our meta-analysis and CT results should be considered for future vector distribution models as well as risk maps for prevention and control measures, especially for our country of study, Nepal. In order to detect temperature-based distribution limits, the acclimation of eggs prior to cold exposure, the effects of fluctuating temperatures and the ecophysiological plasticity regarding cold temperatures should be further investigated in Ae. aegypti. Thus, more populations of Ae. aegypti should be experimentally tested to confirm the results described herein. Until now, only ten populations of this species have been evaluated and the present CT study, to our knowledge, is the first to evaluate eggs from a South Asian population. Additionally, the question has to be raised whether populations of Ae. aegypti from colder eco-regions may even be more (or less) coldhardy than the population examined in the present study. It can be assumed that Ae. aegypti is likely to establish populations in southern Europe and overwinter especially with regard to climate warming which increases minimum temperatures. To give an example, from Italy, the annual minimum monthly temperature in Modena from 1968-1995 was as low as $-2.4^{\circ} \mathrm{C}$ in January and in Foggia as low as $2.9^{\circ} \mathrm{C}$ in February, respectively, whereas under climate change scenarios the minimum temperature is expected to be higher [46]. In consequence, in accordance with the presented results, Ae. aegypti could probably survive throughout the year and re-establish itself in these regions under climate change scenarios.

\section{Conclusions}

Our analysis shows that the reason why Ae. aegypti is presently restricted to subtropical and tropical habitats and lacks permanent populations in especially southern Europe is still unclear. Probably cold winter does not seem to be the limiting factor for this species in southern Europe since Ae. aegypti eggs can survive and develop into viable adults after sub-zero temperature exposure up to $-2{ }^{\circ} \mathrm{C}$ for 6 days. However, Ae. aegypti has been underrepresented in CT testing compared to Ae. albopictus. Therefore, future analyses of CT in Ae. aegypti should include multiple populations from different ecoregions and address different acclimation scenarios, ecophysiologial plasticity and temperature fluctuations in order to obtain more reliable future distribution models and risk maps of this medically highly important species.

\section{Supplementary information}

Supplementary information accompanies this paper at https://doi. org/10.1186/s13071-020-04054-w.

Additional file 1. PRISMA checklist.

Additional file 2: Table S1. Raw data of meta-analysis including raw data of own CT experiment. Table S2. Selected data of meta-analysis including raw data of own CT experiments (own data was not included in analysis). Table S3. Excluded data of meta-analysis and respective exclusion arguments. Table S4. Estimation of exposure time of field studies (meta-analysis). Table S5. Estimation of survivorship or mortality from graphs (meta-analysis). Table S6. Emergence of adults of CT2 experiment per treatment and species.

\section{Abbreviations}

$\mathrm{CT}$ : cold tolerance; NC: negative control; CT1: cold tolerance experiment testing $3{ }^{\circ} \mathrm{C}$ and $0{ }^{\circ} \mathrm{C} ; \mathrm{CT} 2$ : cold tolerance experiment testing $0{ }^{\circ} \mathrm{C},-2{ }^{\circ} \mathrm{C}$ and $-6^{\circ} \mathrm{C} ; \mathrm{F} 1$ : eggs produced from $\mathrm{F} 0$ generation in the laboratory; $\mathrm{F} 2$ : eggs produced from $\mathrm{F} 1$ generation in the laboratory; $\mathrm{Cl}$ : confidence interval; $R^{2}$ : coefficient of determination; $\mathrm{LT}_{50}$ : time when $50 \%$ of eggs did not hatch after treatment; $P$ : $P$-value; DDT: dichlorodiphenyltrichloroethane.

\section{Acknowledgements}

The authors wish to thank Ishan Gautam from the Tribhuvan University (Kathmandu, Nepal) as well as Promod Shrestha, Sunita Baral, Sabita Oli and Keshav Luitel from the Nepal Health Research Council (Kathmandu, Nepal) for the microplanning and conducting of the egg sampling campaign in Nepal and Ute Germann, Goethe University Frankfurt (Germany), for helping with literature search.

\section{Authors' contributions}

IK, RM, MD, AK, UK and DK conceptualized the study. DG and RM supplied facilities and equipment. IK, DK, CS and PP performed the meta-analysis, formal analysis and data curation. IK and AK performed the cold tolerance experiment, laboratory experiment and acquisition of empirical data. IK drafted the manuscript. All authors contributed to the manuscript. All authors read and approved the final manuscript.

\section{Funding}

The work was funded by the Federal Ministry of Education and Research of Germany (BMBF) under the project AECO (Number 01KI1717) as part of the National Research Network on Zoonotic Infectious Diseases of Germany.

\section{Availability of data and materials}

All data generated or analyzed during this study are included in this published article and its additional files.

Ethics approval and consent to participate

Not applicable.

Consent for publication

Not applicable.

\section{Competing interests}

The authors declare that they have no competing interests.

\section{Author details}

${ }^{1}$ Institute of Occupational, Social and Environmental Medicine, Goethe University, Frankfurt am Main, Germany. ${ }^{2}$ Institute for Atmospheric and Environmental Sciences, Goethe University, Frankfurt am Main, Germany. ${ }^{3}$ Nepal Health Research Council, Kathmandu, Nepal. ${ }^{4}$ Unit Entomology, Institute of Tropical Medicine, Antwerp, Belgium.

Received: 22 January 2020 Accepted: 30 March 2020

Published online: 07 April 2020 


\section{References}

1. Souza-Neto JA, Powell JR, Bonizzoni M. Aedes aegypti vector competence studies: a review. Infect Genet Evol. 2019:67:191-209.

2. Schaffner F, Mathis A. Dengue and dengue vectors in the WHO European region: past, present, and scenarios for the future. Lancet Infect Dis. 2014;14:1271-80

3. Toma L, Di Luca M, Severini F, Boccolini D, Romi R. Aedes aegypti: risk of introduction in Italy and strategy to detect the possible re-introduction. Pest Management e salute pubblica. Veterinaria Italiana. Collana di monografie. Monografia 23; 2011. http://www.izs.it/vet_italiana/Colla na_di_Monografie/Mon23_2_Toma.pdf.

4. Almeida APG, Gonçalves YM, Novo MT, Sousa CA, Melim M, Grácio AJS. Vector monitoring of Aedes aegypti in the autonomous region of Madeira, Portugal. Euro Surveillance. 2007;12(E071115):6.

5. Yunicheva YU, Ryabova TE, Markovich NY. First data on the presence of breeding populations of the Aedes aegypti L. mosquito in Greater Sochi and various cities of Abkhazia. Meditsinskaia Parazitologiia I Parazitarnye Bolezni. 2008:3:40-3.

6. Scholte EJ, Den Hartog W, Dik M, Schoelitsz B, Brooks M, Schaffner F, et al. Introduction and control of three invasive mosquito species in the Netherlands, July-October 2010. Euro Surveillance. 2010;15:19710.

7. Caminade C, Medlock JM, Ducheyne E, McIntyre KM, Leach S, Baylis M, et al. Suitability of European climate for the Asian tiger mosquito Aedes albopictus: recent trends and future scenarios. J R Soc Interface. 2012:9:2708-17.

8. Benedict MQ, Levine RS, Hawley WA, Lounibos LP. Spread of the tiger: global risk of invasion by the mosquito Aedes albopictus. Vector-Borne Zoonotic Dis. 2007:7:76-85.

9. European Centre for Disease Preventation and Control (ECDC). Factsheet: Aedes albopictus. https://www.ecdc.europa.eu/en/disease-vectors/facts/ mosquito-factsheets/aedes-albopictus. Accessed 20 Dec 2019.

10. European Centre for Disease Prevention and Control (ECDC). Aedes albopictus, January 2019. https://ecdc.europa.eu/en/publications-data/aedes-albopictus -current-known-distribution-january-2019. Accessed 10 Dec 2019.

11. Medlock JM, Hansford KM, Schaffner F, Versteirt V, Hendrickx G, Zeller H, et al. A review of the invasive mosquitoes in Europe: ecology, public health risks, and control options. Vector Borne Zoonotic Dis. 2012;12:435-47.

12. Paupy C. Aedes albopictus, an arbovirus vector: from the darkness to the light. Mictobes Infect. 2009;11:1177-85.

13. Hanson SM. Cold hardiness of Aedes albopictus eggs. Ph.D. Thesis, University of Notre Dame, Notre Dame, IN, USA; 1991.

14. Hawley AH. The biology of Aedes albopictus. J Am Mosq Control Assoc. 1988:4:2-39.

15. Mori A, Oda T, Wada Y. Studies on the egg diapause and overwintering of Aedes albopictus in Nagasaki. Trop Med. 1981;23:79-90.

16. Romi R, Severini F, Toma L. Cold acclimation and overwintering of female Aedes albopictus in Roma. J Am Mosq Control Assoc. 2006:22:149-51.

17. Kreß A, Oppold AM, Kuch U, Oehlmann J, Müller R. Cold tolerance of the Asian tiger mosquito Aedes albopictus and its response to epigenetic alterations. J Insect Physiol. 2017;99:113-21.

18. Jiang Y. Survival of overwintering Aedes albopictus eggs under natural conditions in North-Central Florida. J Am Mosq Control Assoc. 2018:34:255-9.

19. Medley KA, Westby KM, Jenkins DG. Rapid local adaptation to northern winters in the invasive Asian tiger mosquito Aedes albopictus: a moving target. J Appl Ecol. 2019;56:2518-27.

20. Mogi M. Variation in cold hardiness of nondiapausing eggs of nine Aedes (Stegomyia) species (Diptera: Culicidae) from eastern Asia and Pacific Islands ranging from the tropics to the cool-temperate zone. J Med Entomol. 2011:48:212-22

21. Tadano T. Cold-hardiness of eggs of the mosquito Aedes albopictus (Skuse): among Malaysian and Japanese strains. Trop Biomed. 1990;7:119-24.

22. Thomas S, Obermayr U, Fischer D, Kreyling J, Beierkuhnlein C. Low-temperature threshold for egg survival of a post-diapause and non-diapause European aedine strain, Aedes albopictus (Diptera: Culicidae). Parasites Vectors. 2012;5:100

23. Tippelt $L$, Werner D, Kampen $H$. Tolerance of three Aedes albopictus strains (Diptera: Culicidae) from different geographical origins towards winter temperatures under field conditions in northern Germany. PLoS ONE. 2019;14:e0219553.

24. Hanson SM. Field overwinter survivorship of Aedes albopictus eggs in Japan. J Am Mosq Control Assoc. 1995:11:354-7.
25. Hanson SM, Mutebi JP, Craig GB, Novak RJ. Reducing the overwintering ability of Aedes albopictus by male release. J Am Mosq Control Assoc. 1993:9:78-83.

26. Hanson SM, Craig JRG. Relationship between cold hardiness and supercooling point in Aedes albopictus eggs. J Am Mosq Control Assoc. 1995; 11:35-8.

27. Hanson SM, Craig GB Jr. Cold acclimation, diapause, and geographic origin affect cold hardiness in eggs of Aedes albopictus (Diptera: Culicidae). J Med Entomol. 1994:31:192-201.

28. Hanson SM, Craig GB Jr. Aedes albopictus (Diptera: Culicidae) eggs: field survivorship during northern Indiana winters. J Med Entomol. 1995:32:599-604.

29. Hawley W, Reiter P, Copeland R, Pumpuni C, Craig GJ. Aedes albopictus in North America: probable introduction in used tires from northern Asia. Science. 1987;236:1114-6.

30. Hawley WA, Pumpuni CB, Brady RH, Craig GB. Overwintering survival of Aedes albopictus (Diptera: Culicidae) eggs in Indiana. J Med Entomol. 1989;26:122-9.

31. Rozeboom LE. The overwintering of Aedes aegypti L. in stillwater Oklahoma. In: Acad Sci. 1938;81-2.

32. Bacot AW. Report of the entomological investigation undertaken for the Commission for the year, August 1914- to July 1915. Yellow Fever Comm. 1916:3:1-191.

33. Bond HA, Keirans JE, Merle FB. Environmental influences on the viability of overwintering Aedes aegypti (L.) eggs. Mosq News. 1970;30:528-33.

34. Davis NC. The effects of heat and of cold upon Aedes (Stegomyia) aegypti. Am J Epidemiol. 1931;16:177-91.

35. Hatchett SP. Winter survival of Aedes aegypti (L.) in Houston, Texas. Public Health Rep. 1946:61:1234-44.

36. Reed W, Owen M. Yellow fever - a compilation of various publications. In: Owen M, editor. Washington: Washington Government Printing Office; 1911.

37. Craig GBJ, Hawley WA. The Asian tiger mosquito, Aedes albopictus: whither, whence, and why not in Virginia? In: Centennial of Entomology at Virginia Polytechnic University, Blacksburg, 6-10 September 1991.

38. RStudio Team. RStudio: integrated development for R. RStudio, Inc., Boston, MA. 2015. http://www.rstudio.com/. Accessed 10 Nov 2019.

39. Kreß A, Kuch U, Oehlmann J, Müller R. Impact of temperature and nutrition on the toxicity of the insecticide $\lambda$-cyhalothrin in full-lifecycle tests with the target mosquito species Aedes albopictus and Culex pipiens. J Pest Sci. 2014;87:739-50.

40. Müller R, KnautzT, Volker J, Kreb A, Kuch U, Oehlmann J. Appropriate larval food quality and quantity for Aedes albopictus (Diptera: Culicidae). J Med Entomol. 2013;50:668-73.

41. Christophers RS. Aedes aegypti (L.) the yellow fever mosquito-its life history, bionomics and structure. Regulatory risk and the cost of capital: determinants and implications for rate regulation. London: Cambridge University Press; 1960.

42. Hoffmann AA, Ross PA. Rates and patterns of laboratory adaptation in (mostly) insects. J Econ Entomol. 2018;111:501-9.

43. Ross PA, Endersby-Harshman NM, Hoffmann AA. A comprehensive assessment of inbreeding and laboratory adaptation in Aedes aegypti mosquitoes. Evol Appl. 2019;12:572-86.

44. Fischer S, De Majo MS, Di Battista CM, Montini P, Loetti V, Campos RE. Adaptation to temperate climates: evidence of photoperiod-induced embryonic dormancy in Aedes aegypti in South America. J Insect Physiol. 2019;117:103887

45. Zhang D, Xi Z, Fan Y, Zheng X, Li Y, Wu Y, et al. Water-induced strong protection against acute exposure to low subzero temperature of adult Aedes albopictus. PLoS Negl Trop Dis. 2019;13:e0007139.

46. Tubiello FN, Donatelli M, Rosenzweig C, Stockle CO. Effects of climate change and elevated $\mathrm{CO}_{2}$ on cropping systems: model predictions at two Italian locations. Eur J Agron. 2000;13:179-89.

47. Kraemer MUG, Sinka ME, Duda KA, Mylne AQN, Shearer FM, Barker CM, et al. The global distribution of the arbovirus vectors Aedes aegypti and Ae. albopictus. Elife. 2015;4:e08347.

\section{Publisher's Note}

Springer Nature remains neutral with regard to jurisdictional claims in published maps and institutional affiliations. 